\title{
EFECTOS ECOLÓGICOS DEL DRAGADO Y VACIADO DEL EMBALSE DE BARASONA
}

\author{
Joan Armengol \\ Dep. d'Ecologia. Facultat de Biologia. Universitat de Barcelona. Avda. Diagonal, 645. 08028-Barcelona.
}

\section{RESUMEN}

El ciclo anual del embalse de Barasona durante los años 1994-95 ha estado condicionado por tres procesos que se han superpuesto en el tiempo. En primer lugar se encuentra la variabilidad estacional debida a la climatología de la Península. La alternancia de periodos de estratificación y mezcla se combina con las fases de producción y respiración. En segundo lugar destaca la utilización del embalse como abastecimiento para regadío que produce un vaciado del mismo hasta la cota mínima de utilización durante los meses de estiaje. Por último, en los dos años estudiados se ha producido un dragado del embalse y su posterior vaciado total. En este trabajo se diferencian, mediante un Análisis de Componentes Principales (ACP) $l a$ influencia de estos tres procesos en la variabilidad temporal.

El dragado del embalse en las proximidades de la presa ha permitido estudiar el efecto de la resuspensión de los sedimentos en la variabilidad espacial del embalse a lo largo de su eje principal.

Palabras clave: dragado, desembalse. ciclo anual, sedimentos. heterogeneidad espacial

\section{ABSTRACT}

The annual cycle of the reservoir of Barasona iri $1994-95$ period was influenced by three simultaneous processes. A first one was the seasonal variability produced by the Mediterranean weather. The alternancy of stratification and mixing was combined with periods where production or respiration were the dominant biological processes. Second, the emptying of the reservoir was kept up to the minimum useful level for irrigation during the summer months. Finally, the reservoir was dragged and later fully emptied. In this study it has been possible to differentiate, by means of a Principal Component Analysis, the importance of each one of the previous cited processes iti the temporal variability of the reservoir water.

The aragging of the reservoir in an area close to the dam made possible to study the effect of the resuspended sediment on the spatial variability along its mains axis.

Key words: dredging, reservoir flushing, annual cycle, sedimen, spatial heterogeneity.

\section{INTRODUCCIÓN}

El dragado de los embalses tiene como finalidad el mantenimiento de su capacidad de uso al máximo rendimiento posible. Los embalses, al igual que los lagos, son cubetas de decantación de los sólidos en suspensión que transporta el río desde la cuenca de drenaje. Este proceso se encuentra con frecuencia acelerado por varias razones, siendo la más importante su carácter artificial que lo hace no estar en equilibrio con su cuenca de drenaje. La actividad humana en la cuenca, y en general todos aquellos procesos que aumenten la erosión de la cuenca, tienden a reducir la vida del embalse por colmatación de la cubeta.

Aunque los motivos del dragado pueden ser múltiples, (Cooke et al., 1993) señala cuatro causas por las que se suelen dragar los embalses:
1.- Aumentar la profundidad e incrementar la capacidad del embalse. Solo es aplicable a lagos pequeños en los que el volumen de sedimentos retirados no suponga un problema grave de almacenamiento en otras zonas. Se han realizado múltiples intentos de reutilización de estos sedimentos para regeneración de suelos, aunque con escaso éxito por predominar los materiales arcillosos que impermeabilizan y reducen la textura del suelo. Para sistemas de gran volumen se suelen dragar ciertas zonas por motivos operacionales (navegación, reparación de compuertas, etc.).

2.- Control de nutrientes. Los sedimentos son zonas de acumulación de nutrientes. Parte del material sedimentado es orgánico, que contiene nitrógeno amoniacal y fósforo. Paralelamente, se puede producir precipitación de diferentes compuestos de fósforo que tienen solubilidades muy 
bajas y que por lo tanto son retirados de circulación (Armengol et al., 1986). Este proceso es tanto más importante cuanto más eutrófico es el embalse (Margalef, 1983) constituye uno de los mecanismos de autodepuración de los ecosistemas acuáticos. Si los embalses son someros, puede producirse una resuspensión por efecto del viento, mientras que si los sedimentos son limos o arenas pueden liberarse parte de los nutrientes acumulados. En ambos casos el carácter eutrófico de los embalses persiste como consecuencia de la recirculación de los nutrientes entre el agua y el sedimento (Nurnberg, 1984; Nurnberg \& Peters, 1984).

3.- Retirada de substancias tóxicas. Como se acaba de mencionar el sedimento es la zona de acumulación de muchos de los materiales que se encuentran en el agua. Además de los nutrientes, muchos metales tienden a precipitar en condiciones oxidantes y de elevado $\mathrm{pH}$ o potencial de oxido-reducción. Aunque las concentraciones en el agua puedan ser bajas, el carácter acumulativo del sedimento los hace potencialmente peligrosos en caso de movilización en condiciones químicas adecuadas, como ocurrió con la enfermedad de Minamata producida por acumulación de mercurio. De forma similar se puede decir lo mismo con respecto a la materia orgánica tóxica. Mientras las tasas de sedimentación sean elevadas y los sedimentos arcillosos, la materia orgánica queda enterrada en los mismos y con escasas posibilidades de retorno al agua, pero puede retornar al medio si los sedimentos son porosos y las condiciones oxidantes. El estudio detallado de las especies orgánicas que se hallan en el sedimento muestra que una parte no despreciable de la materia orgánica puede ser tóxica (hidrocarburos, pesticidas, etc.). El caso más reciente y espectacular por su dramatismo es la contaminación de los Grandes Lagos de Norteamérica por policloruros bifenilos (PCB's).

4.- Una de las causas que determinan el dragado total o parcial de una zona de los embalses es la erradicación de los macrófitos enraizados en las zonas litorales. Afortunadamente, este fenómeno no es muy frecuente en España ya que los embalses tienen grandes fluctuaciones de nivel que imposibilita el desarrollo de macrófitos en la zona litoral o en la cola de los embalses. Antes al contrario, se tiende a estimular su crecimiento siempre que las posibilidades lo permiten, ya que en nuestro caso los cinturones de vegetación pueden actuar como zonas de sedimentación y como filtros biológicos.

Es evidente que el dragado del embalse de Barasona se inscribe dentro del primer punto ya que se pretende acceder a determinadas infraestructuras (desagües de fondo), repararlas para mantener la capacidad operacional plena del embalse y aumentar las condiciones de seguridad de la presa. Los puntos 2 y 3 tienen, en este caso, un carácter potencialmente negativo ya que, por las condiciones del embalses y el tipo de sedimento, el dragado podría representar la movilización de nutrientes y materiales tóxicos acumulados a lo largo de toda la vida del embalse y que hasta el momento no habían manifestado ningún efecto negativo.

Según el planteamiento anterior, la hipótesis de trabajo para seguir el efecto del dragado del embalse es que se puede producir una liberación parcial de los nutrientes y otras substancias tóxicas acumuladas en el sedimento y un aumento de la turbidez y de los sólidos en suspensión. En realidad se trata de una serie de efectos antagónicos sobre la producción primaria del embalse y que pueden afectar de forma desigual a toda la cadena trófica (zooplancton filtrador, zooplancton carnívoro y peces).

El aumento de la turbidez y de los sólidos en suspensión produce un cambio importante en el clima lumínico, que puede llegar a afectar a la zona fótica, reduciendo la penetración de la luz. De forma paralela es previsible que el aumento de los nutrientes (amonio y fósforo) pueden producir un incremento de la producción en las zonas en las que llegue luz suficiente. Finalmente, si la concentración de substancias tóxicas y metales pesados se incrementa, el efecto sobre las comunidades planctónicas será negativo. Es indudable que todos estos efectos no tienen porque darse de forma simultánea, es más, incluso pueden ser despreciables, pero, en cualquier caso, constituyen una serie de hipótesis de trabajo que deberán ser verificadas mediante el seguimiento de diferentes variables ambientales representativas.

Para el desarrollo práctico del vaciado de Barasona y su efecto en la ecología del embalse y del río en su tramo inferior se ha seguido el procedimiento "LIVE" (Limitación del Impacto del Vaciado de Embalses) (Cardinal, 1989). Según 
este procedimiento las variables ambientales que reflejaran mejor el efecto del vaciado y que a su vez inciden en mayor medida en la calidad del agua son: los sólidos en suspensión y las concentraciones de amonio, oxígeno hierro y manganeso, además de las variaciones del $\mathrm{pH}$. En este estudio estas variables se han seguido de forma prioritaria. No obstante, se ha incluido una caracterización mucho más completa a partir de otras variables ambientales con el fin de observar la posible existencia de efectos sinérgicos o de la existencia de variables que, sin ser tan evidentes, permiten realizar un seguimiento del efecto vaciado de forma más sencilla o precisa.

El vaciado de un embalse hay que situarlo dentro del ciclo anual de variabilidad ambiental. Un embalse es un ecosistema y como tal responde a los cambios externos (aportes de agua, energía y todos los materiales sólidos o disueltos que pueda aportar el río). Además, se autorganiza mediante una serie de procesos internos, en los que los organismos juegan un papel muy importante a través del balance producciónírespiración. En síntesis, los ciclos biogeoquímicos de los elementos que se encuentran en el embalse tienen una variabilidad temporal natural en la que hay que inscribir los efectos producidos por el vaciado del embalse. En este sentido, el seguimiento de los cambios ambientales tiene como objetivo evaluar:

- La variabilidad natural del embalse.

- El efecto de los trabajos de dragado "in situ" previos a la abertura de las compuertas de fondo.

- Obtener un punto de referencia en el que situar el efecto concreto y a corto plazo del vaciado del embalse.

\section{ÁREA DE ESTUDIO}

El embalse de Barasona se halla situado en la vertiente sur de los Pirineos, a $447 \mathrm{~m}$ sobre el nivel del mar. Su cuenca de drenaje es de 1500 $\mathrm{km}^{2}$ y está recorrida por los río Esera e Isábena, que aportan respectivamente el $76 \%$ y $24 \%$ del caudal entrado. Las características morfológicas más importantes del embalse pueden verse en la Tabla 1 y la forma del embalse en la figura 1 , no obstante, la morfología de la cubeta se puede expresar mucho mejor mediante las curvas hipso-
Tabla 1. Situación del embalse de Barasona y principales características morfométricas e hidrológicas. Locution of the Barasona reservoir and main morphologic and hydrological features.

\begin{tabular}{lr}
\hline Latitud & $420730 \mathrm{~N}$ \\
\hline Longitud & $035955 \mathrm{E}$ \\
\hline Altura (m.s.n.m) & 447 \\
\hline Superficie de la cuenca (km2) & 1500 \\
\hline Superficie del embalse (ha) & 692 \\
\hline Volumen (hm3) & 92 \\
\hline Profundidad máxima (m) & 16.46 \\
\hline Profundidad media (m) & 832 \\
\hline Flujo total (hm3/año) & $632(76 \%)$ \\
\hline Flujo Ésera (hm3/año) & $200(24 \%)$ \\
\hline Flujo Isábena (hm3/año) & 90 \\
\hline
\end{tabular}

gráficas de superficie y volumen se muestran en la figura 2. La capacidad máxima nominal del embalse se incrementó en 1972 por el recrecimiento de la presa desde $70 \mathrm{hm}^{3}$ hasta $92 \mathrm{hm}^{3}$, aunque posteriormente se ha visto reducida por los sedimentos transportados por el río y debido a la elevada erosionabilidad de la cuenca. En 1988 se consideraba que los sedimentos ocupaban un volumen de $5 \mathrm{hm}^{3}$. La empresa concesionaria del embalse (Hidro-Nitro) ha realizado vaciados en 1973 y 1978 con el objetivo de eliminar parte de los sedimentos acumulados en Barasona.

En la figura 1 se pueden ver la localización de los diferentes puntos de muestreo del embalse de Barasona. La estación C 1 se ha usado como referencia para seguir los efectos del dragado. Se encuentra situada en el eje principal del embalse y en las proximidades del punto de dragado. En ella se ha realizado el estudio de todas las variables físicas, químicas y biológicas que constituyen la base de datos para la realización de este informe. Las restantes estaciones se han ido situando a medida que se necesitaba información complementaria para tener una visión lo más completa posible de todo el embalse. La información disponible de las estaciones complementarias (L1, L2 y $\mathrm{C} 2$ a $\mathrm{C} 4$ ) ha permitido conocer hasta que punto los datos de la $\mathrm{C} 1$ eran el resultado del dragado o de los aportes de los ríos Ésera e Isábena, mientras que las estaciones laterales 


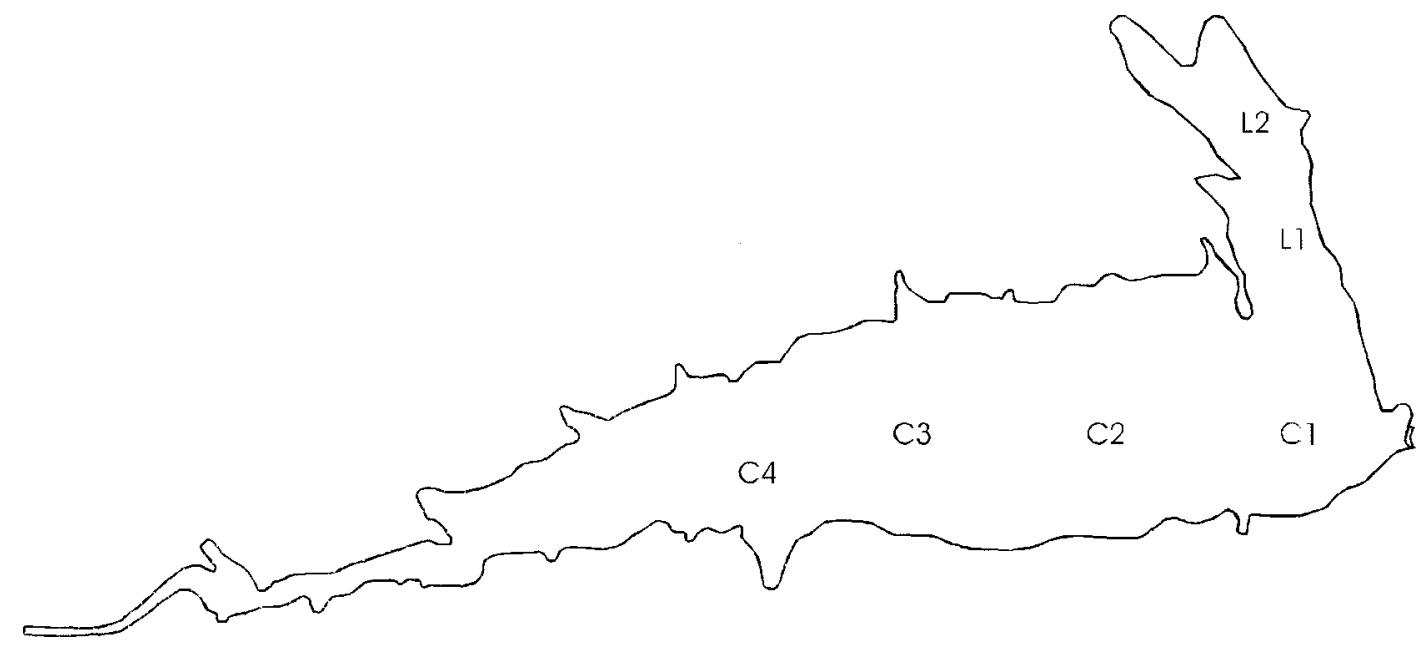

Figura 1. Ubicación de las estaciones de muestreo en el embalse dc Barasona. La estación C1. la más cercana al punto de dragado se ha toma» do como referencia para el estudio físico, químico y biológico del embalse. Position of the samplig stations in the reservoir of Barasona. The data obtained in the station $\mathrm{Cl}$, the closest to the dredging point, has been ased for thr physical, chemical and biological study of the reservoir.

(L1 y L2) tenían idéntica función con respecto al río Salado.

\section{MATERIAL Y MÉTODOS}

El estudio de Barasona se ha centrado básicamente en la estación Cl (Fig. i), en la que se han realizado los análisis químicos completos y se han recogido muestras de plancton. No obstante, en cada campaña de muestreo se han realizado transectos hacia la cola del embalse y del brazo correspondiente a la entrada del río Salado. Los muestreos se han efectuado con una periodicidad mensual, a excepción de íos meses de verano, por estar el embalse a la cota mínima de utilización y no poder acceder a la estación, y en noviembre de 1994 que se retrasó el muestreo hasta principios de diciembre. Esta demora a finales de año se debe a que en los meses posteriores a la fase de mezcla otoñal los cambios que se producen en la columna de agua son generalmente mucho más pausados, no reflejan un gran dinamismo en la actividad biológica, y, en el caso concreto de Barasona, corresponden al período de inactividad en el dragado.
Dado que la estratificación vertical, tanto térmica como química, es muy intensa en los embalses, se ha seguido la estrategia de hacer un muestreo a profundidades variables en función de la existencia de discontinuidades (clinas) medidas previamente con detalle. Estas mediciones detalladas de ciertas variables clave han sido igualmente la base del estudio de la heterogeneidad especial del embalse. En todas las estaciones de la figura 1, cuando la profundidad del agua lo ha permitido, y en la estación $\mathrm{C} 1$ siempre, antes del muestro se ha medido metro a metro la temperatura, el pH, el oxígeno (absoluto y en tantos por ciento de saturación), la conductividad eléctrica del agua, la turbidez y el potencial redox con una sonda multiparamétrica YSI-Grant modelo 3800 Water Quality Logging System. Con los perfiles obtenidos se han elegido las profundidades más representativas de cada capa de agua y en ellas se tomaban las muestras para los análisis químicos. Los datos obtenidos mediante el análisis del agua a diferentes profundidades se han interpolado mediante "spline" cúbica (Press et al., 1989) a todas las intermedias metro a metro y éstos han sido los datos utilizados para los análisis posteriores. 
La evolución temporal de las diferentes variables estudiadas se ha realizado calculando en primer lugar los valores medios de la estación C1, ponderados, según la morfología del embalse. para las profundidades maestreadas. Es decir, se han utilizado las curvas hipsográficas para calcular la masa o el valor de una variable para todo el embalse y después se ha dividido por el volumen de agua embalsado en cada momento. A partir de estos resultados se han calculado los valores teóricos para cada día del año por interpolación trapezoidal y, por ultimo, a partir de los valores diarios se han calculado las medias mensuales para cada variable. Desde el punto de vista estadístico se ha utilizado básicamente el programa SPSS o las subrutinas del tratamiento estadístico EXCEL 4.

Los procedimientos seguidos para la determinación de las diferentes variables se pueden considerar de uso general y el protocolo detallado de los métodos seguidos o de otros alternativos, igualmente válidos, pueden encontrarse en muchos de los libros metodológicos existentes (Golterman et al., 1978, Mackereth et al., 1978, APHA \& Association., 1989, Wetzel \& Likens, 1991). En cada muestra de agua se han analizado las siguientes variables: alcalinidad, sulfatos, cloruros, calcio, magnesio, sodio, potasio, amonio, nitrito, nitratos, ortofosfato reactivo soluble, nitrógeno y carbono particulado, nitrógeno y fósforo total, hierro, aluminio, manganeso y zinc, clorofila a , se ha medido la peiietración de la luz, los sólidos en suspensión y se han calculado los índices pigmentarios (D430/665), la concentración de carbonatos, bicarbonatos y la presión parcial de CO,.

\section{RESULTADOS}

\section{Ciclo anual}

Barasona forma parte del centenar de embalses españoles que se han estudiado para realizar la clasificación del conjunto de los construidos hasta el momento en España. Este estudio ha tenido dos fases, la primera realizada entre 1972 y 1975 (Margalef, 1975; Margalef et al., 1976) en la que se hizo la clasificación y una segunda entre 1987 y 1988 en la que se estudiaron los posibles cambios en dicha clasificación debido a la actividad humana durante los Últimos 15 años (Morguí et al., 1990; Riera et al., 1992). Según estos estu-
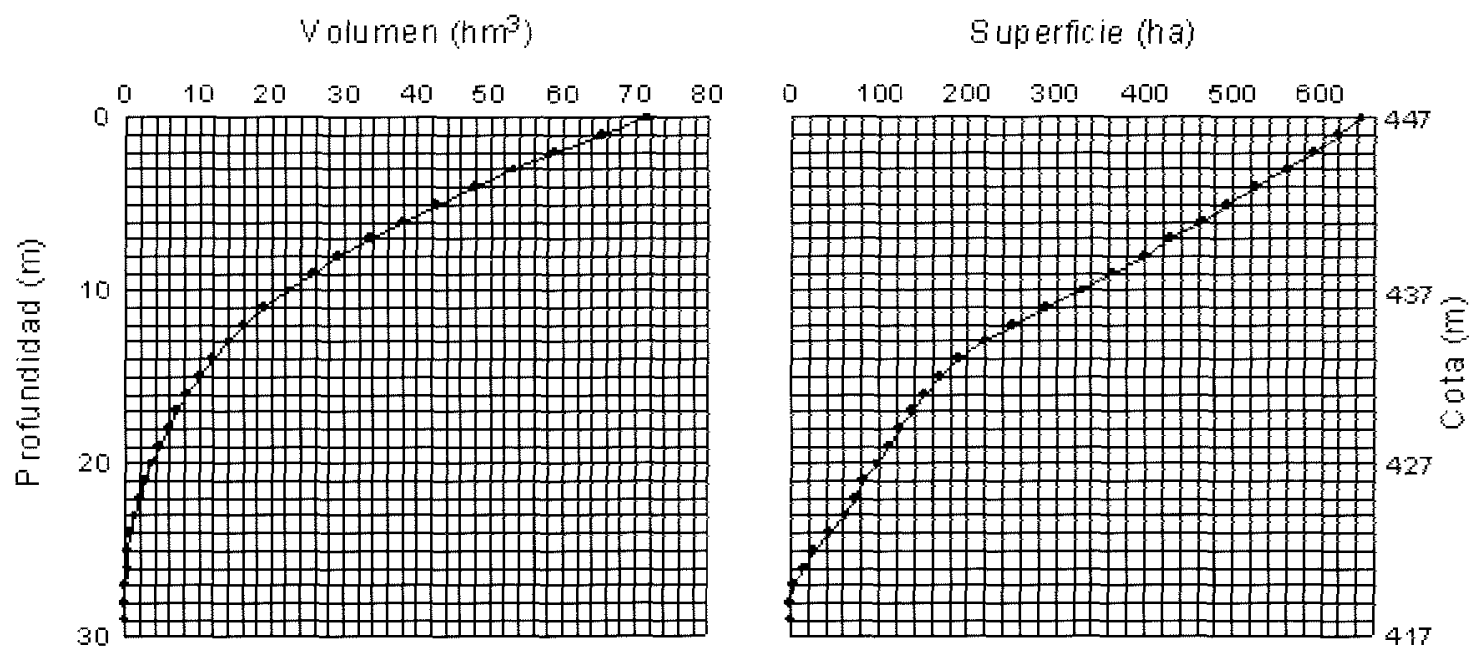

Figura 2. Curvas hipsográficas profundidad / superficie y profundidad / volumen del embalse de Barasona. Según datos facilitados por el CEDEX. Hypsographic curves depth/surface and depth/capacity of the reservoir of Barasona. According with the data obtained of the CEDEX. 
dios Barasona pertenece al grupo II de la clasificación de los embalses por su composición iónica mayoritaria (Armengol et al., 1991) y por sus características tróficas es oligo-mesotrófico (Morguí et al., 1990; Riera et al., 1992).

Según la doble clasificación que se ha mencionado Barasona tiene aguas bicarbonatadas $\left(\mathrm{HCO}_{3}{ }^{-}+\mathrm{CO}_{3}{ }^{=}<\mathrm{SO}_{4}{ }^{=}<\mathrm{Cl}-\right)$ con una concentración de sólidos totales disueltos que para el conjunto de embalses deL grupo II se sitúa entre 150 y $450 \mathrm{mg} / \mathrm{L}$ y se hallan principalmente en la zona de la cordillera Cantábrica y los Pirineos. Como catión más importante se halla el calcio, que junto con los bicarbonatos, confiere al agua una elevada capacidad de tamponamiento frente a los cambios de $\mathrm{pH}$. El embalse recibe unos aportes de nutrientes y de materia orgánica poco importantes por los ríos Esera e Isábena debido al escaso desarrollo industrial y la baja densidad humana que se da en toda la cuenca. Esta situación contribuye a mantener su estado trófico en un nivel muy bajo, de tal manera que no es exagerado decir que la mayor fuente de nutrientes son los vertidos de Graus y su área de influencia.

El ciclo anual de Barasona se ha estudiado mediante la realización de un análisis factorial de los datos recogidos para las 22 variables estudiadas a lo largo de los años 1994 y 1995, que correspondieron respectivamente al dragado y vaciado del embalse. Los resultados del análisis factorial se resumen en la denominada matriz factorial, que está formada por los coeficientes de correlación entre los factores y las variables originales. Las columnas de esta matriz son los vectores propios y los resultados obtenidos para los tres primeros factores, están representados en la Tabla 2 junto con el porcentaje de la varianza total de todos los datos utilizados en el análisis que explica cada uno.

En las figuras 3 y 4 se han representado las variables originales en el espacio definido respectivamente por el primer y segundo factor (Fig. 3 ) y por el primer y tercer factor (Fig. 4). Es importante recordar que las coordenadas de cada variables son los factores de correlación con los factores que definen el espacio. Igualmente la proximidad de dos variables originales significa que ambas presentan una correlación elevada. Como resultados significativos del análisis se han escogido los tres primeros ejes, no solo por un criterio de interpretabilidad, sino porque la va-
Tabla 2. Correlaciones entre los tres primeros factores resultantes del ACP y las variables utilizadas en el análisis. Se han eliminado los valores inferiores a 0.2. En la última fila se indica el tanto por ciento de la varianza explicado por cada eje. Correlation coefficients between the three first axes of the PCA and tlie variables used in the analysis. There are not indicated values lesser than 0.2. In ihe last row it is indicaied tlir percentage of the variance explained by each axis.

\section{F1}

Oxígeno
Bicarbon

Bicarbonato

Hierro

Conductividad

Carbonato

Temperatura

Magnesio

Calcio

pH

Potasio

Sólidos Susp

Nitrato

C02

Cloruro

Amonio

Sodio

Sulfato

Nitrito

Clorofila

Carbono Part.

Fosfato

Nitrógeno Part

$\%$ de la varianza

explicada
0.857

0.818

$-0.797$

0.764

$0.75 !$

$-0.743$

0.738

0.708

0.632

0.625

$-0.618$

0.613

$-0.379$

0.412

0.243

0.530

0.442

297

$-0.297$

0.235

$-0.286$

33.7
F2

$-0.385$

$-0.363$

$-0.533$

0.491

0.483

$-0.419$

$-0.590$

0.516

0.360

$-0.165$

0.456

$-0.527$

0.433

0.343

0.029

0.444

$-0.291$

0.456

$-0.370$

0.364

$-0.398$

0.433

0.330

0.469

0.307

0.653

0.584

0.572

0.533

0.457

0.439

$-0.282$

0.522

15.0 rianza explicada por cada uno de ellos es lo suficientemente importante como para estar asociado a un proceso que se puede considerar importante dentro de la dinámica anual del embalse.

El primer eje explica el $33,7 \%$ de la varianza, es decir, un tercio de la variabilidad total de la matriz de datos puede ser explicada por un solo factor. Una interpretación tentativa del significado de este eje se basa en la agrupación antagónica de una serie de variables fuertemente correlacionadas con el primer eje. Como puede verse en la figura 3 el primer eje agrupa en el extremo positivo la concentración de oxígeno, la conductividad, el $\mathrm{pH}$ y una serie de variables asociadas con la mineralización (carbonatos, bicarbonatos, cationes mayoritarios). La separación del oxíge- 


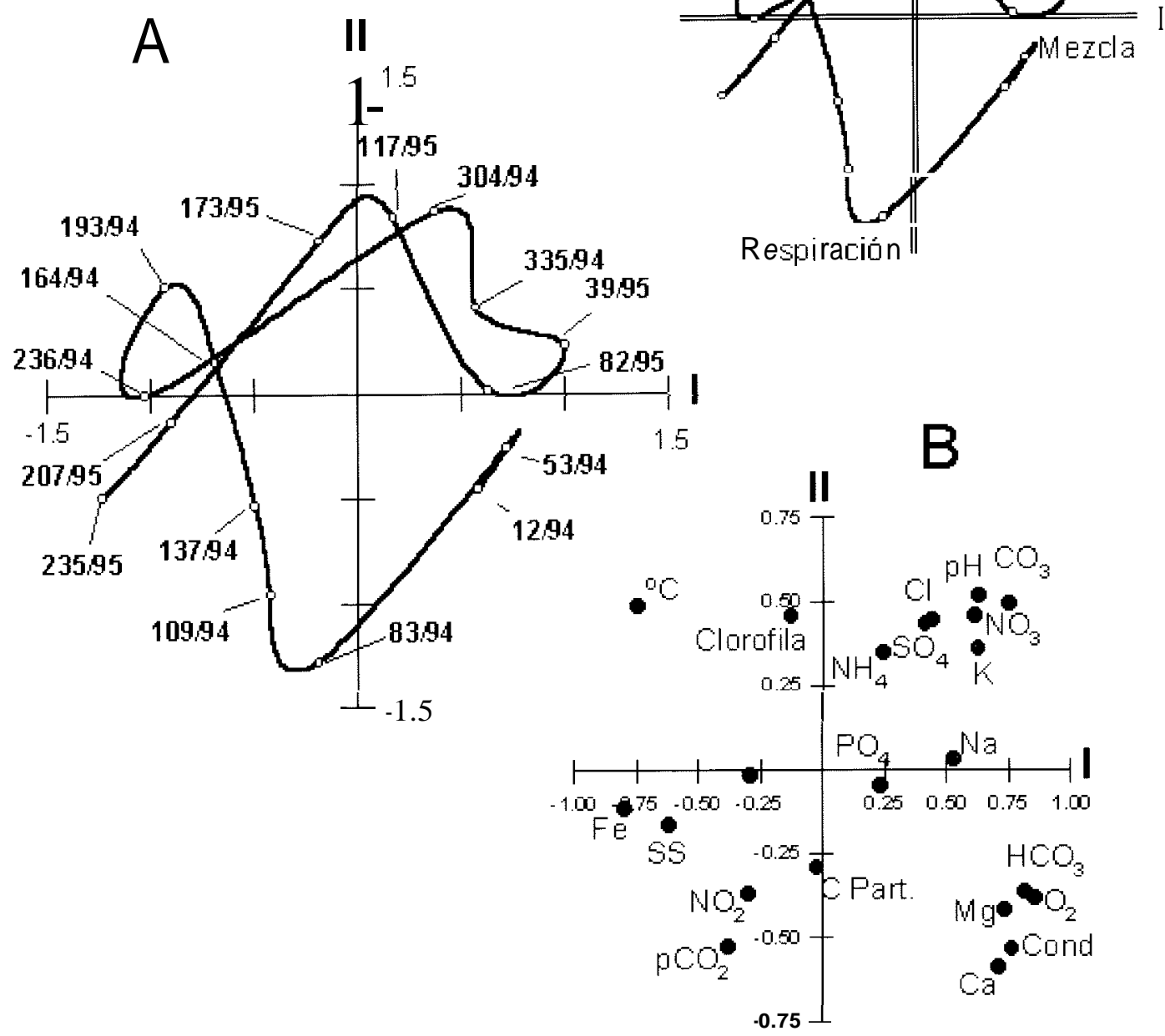

Figura 3. Ciclo anual del embalse de Barasona definido por la evolución temporal de una serie de variables físicas y químicas analizadas o medidas en la estación C1.A) Diagrama de la evolución temporal de las muestras correspondientes a la estación Cl en el espacio definido por los dos primeros ejes del ACP. Cada muestra esta representada por el día juliano y el año (juliano/año). B) Distribución de las variables estudiadas en el espacio definido por los dos primeros ejes que han resultado del ACP. C). Interpretación de los procesos físicos, químicos y biológicos asociados a los dos primeros ejes del ACP. Annual cycle of the reservoir of Barasona defined by the temporal evolution of the physical and chemical variables analyzed or measured in station CI. A) PCA ordination diagram of the temporal evolution of samples taken in station $\mathrm{Cl}$. The Julian day and $\mathbf{t h r}$ year (Julian/year) represent each sample. B) Distribution of the studied variables in thr space defined the two first axis of the PCA. C) Interpretation of the physical, chemical and biological processes defined by the PCA analysis. 
no en un extremo y de la temperatura en el otros es un elemento muy clarificador para conocer el posible significado del eje. En invierno la temperatura del agua es baja, la columna del agua esta mezclada y por lo tanto saturada de oxígeno. En verano se produce la situación contraria, el agua se calienta y estratifica y la concentración de oxígeno media de la columna de agua presenta el mínimo anual. Se trata pues de un eje asociado a un cambio estacional que tienen como valores extremos al verano en la izquierda y el invierno a la derecha, mientras que primavera y otoño se sitúan en la parte central del eje. Las variables asociadas a la mineralización del agua tienen un comportamiento similar al del oxígeno, es decir, descienden desde el invierno al verano como consecuencia de la reducción en los aportes de agua del Isábena a lo largo de este período. Un comportamiento similar presentan todos los iones mayoritarios, que determinan la mineralización del agua y por tanto su conductividad. En resumen, el primer eje tiene una componente estacional marcada y agrupa variables que presentan sus valores extremos en invierno o en verano.

El segundo eje explica el $15.5 \%$ de la varianza y por tanto hay una reducción importante de la información asociada a este eje y de los procesos que tienen lugar en el embalse. Las variables originales presentan una correlación mucho menor con el segundo eje, pero entre ellas destacan las que se asocian al sistema carbónico-carbonato. Efectivamente, en la parte positiva del eje se sitúan los carbonatos y el pH, mientras que en la negativa están la presión parcial de $\mathrm{CO}$, y los bicarbonatos. El sistema carbónico-carbonatos tiene un comportamiento contrapuesto respecto a sus extremos y en relación con el pH y el balance produción-respiración. Valores altos de $\mathrm{pH}$ desplazan el sistema hacia el predominio de los carbonatos en detrimento del anhídrido carbónico, ácido carbónico y los bicarbonatos. Igualmente, la producción hace aumentar el pH y aumenta concentración de carbonatos mientras que la respiración incrementa la concentración de $\mathrm{CO}$, y ácido carbónico. Según este esquema cobra sēntido que el lado positivo del segundo eje se sitúe, junto con el pH y los carbonatos, la concentración de clorofila, mientras que en el extremo opuesto junto con el $\mathrm{CO}$, se halle la concentración de carbono orgánico particulado, que es el susceptible de ser respirado.
Finalmente, el tercer eje explica el $15 \%$ de la varianza, es decir, una proporción muy similar a la del segundo eje. A diferencia de los ejes anteriores presenta todas las variables muy agrupadas en el extremo positivo y con pocas variables antagónicas en el extremo opuesto y, además, con correlaciones muy bajas (Fig. 4). Las variables originales más representativas asociadas al tercer eje son la concentración de amonio, de nitrito, de carbono y nitrógeno particulado, la presión parcial de $\mathrm{CO}$, y la clorofila. En conjunto constituyen una serie de variables ligadas al agua más cercana al fondo del embalse y por tanto más próxima al sedimento. En un embalse como Barasona en que la concentración de oxígeno es siempre elevada, la presencia de compuestos reducidos asociados a materia orgánica solo pueden mantenerse si hay un aporte continuo desde el sedimento y esto solo se produce cuando hay agitación del sedimento por dragado o cuando el nivel del agua desciende y el sedimento de la orilla y la cola es removido por la agitación del agua. Resumiendo, la asociación de las variables parece apuntar hacia un proceso asociado al sedimento.

\section{Variabilidad natural y efecto del dragado}

Como se ha mencionado, uno de los objetivos de este estudio es conocer el efecto del dragado de Barasona y su diferenciación de los cambios que se producen de forma natural a lo largo del año. Dentro de estos últimos hay que considerar los que son una consecuencia directa del clima, períodos de mezcla y estratificación, cambios en la actividad de los organismos, etc. de aquellos que son una consecuencia de la gestión del embalse, que sin ser "naturales" en el sentido de los anteriores, se ajustan a la función del embalse como abastecedor de agua para regadío. En este sentido, el vaciado del embalse hasta la cota mínima de utilización durante el período de regadío se considera como un cambio natural por su carácter repetitivo año tras año y por tanto es una característica importante en el funcionamiento de Barasona como un ecosistema. Otro tema completamente diferente es el dragado del embalse, que supone una perturbación fuera del contexto de los cambios que se producen a lo largo del año. El carácter excepcional de esta perturbación y la magnitud que podía tener en el contexto de un sistema oligo-mesotrófico es el que hacia suponer que se podían producir variaciones impor- 

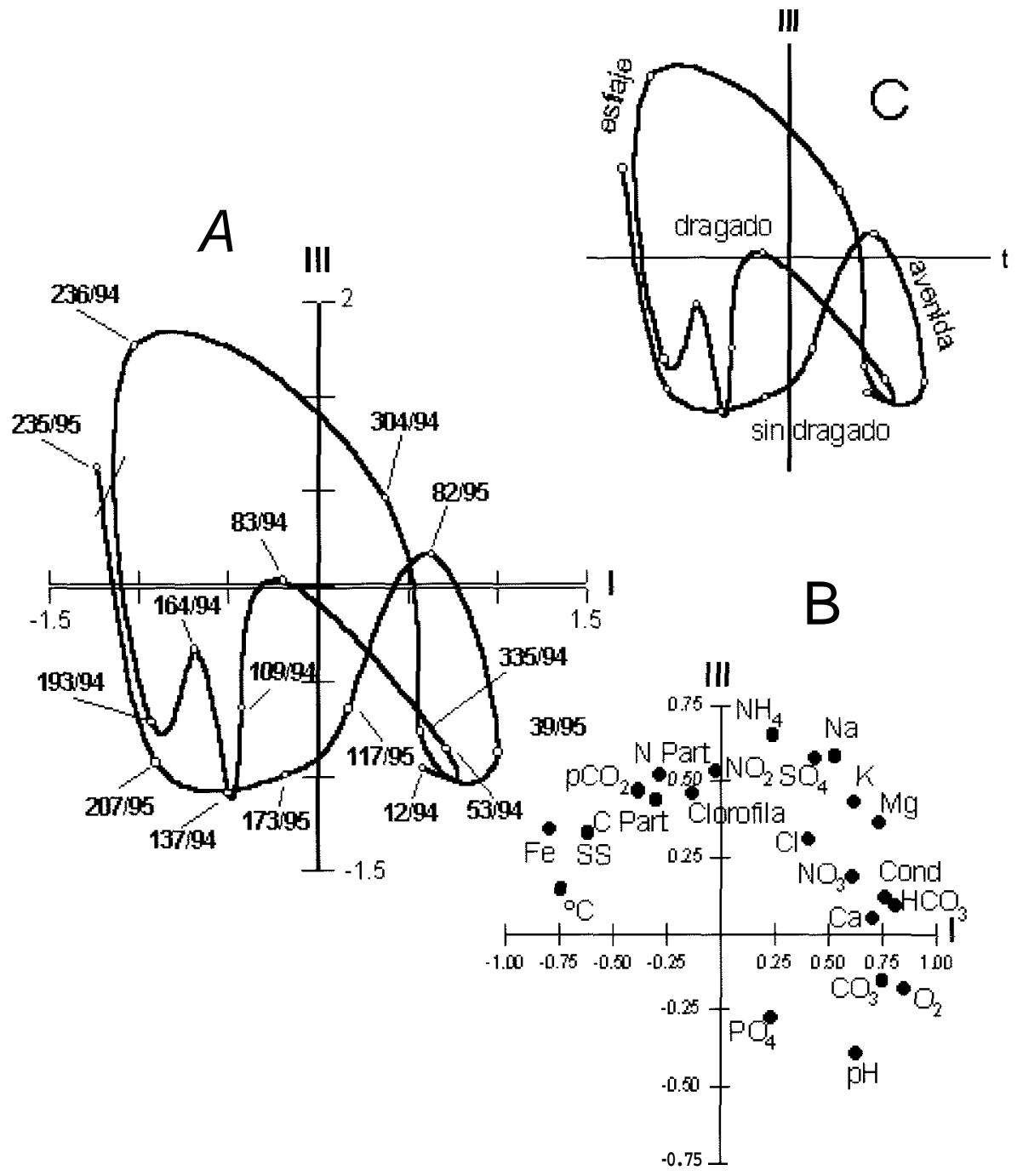

Figura 4. A) Distribución de los valores muestrales de las variables I y III en el espacio definido por dichos Factores. B) Contribución de las variables estudiadas en la definición de los factores 1 y III. C) Interpretación de los resultados. El dragado del embalse aparece como un bucle pequeño caracterizado por concentraciones algo más elevadas de las esperables en esta época del año, de amonio, nitrógeno y carbono particulado, así como de un incremento de la respiración (pCO2). Se puede apreciar que este bucle desaparece en la misma época de 1995 en la que no hubo ninguna actuación directa sobre el sedimento. El vaciado del embalse hasta su cota mínima de utilización durante los veranos de 1994 y 1995 produjo una alteración mucho mayor como resultado del secado de los sedimentos de la orilla y la cola del embalse al irse vaciando. A) Temporal distribution of the samples taken in station $\mathrm{Cl}$ in the PCA ordination diagram defined by I and III axis. B) Distribution of the studied variables in the space defined by the axis I and III that results of the PCA. C) Interpretation of the results. The dragging of the reservoir appears as u small loop characterized by higher concentration than expected of ammonium, particulate carbon and nitrogen, as well as an increase of respiration ( $\mathrm{pCO}$ ). It is possihle to see that this loop disappears in the sume period of 1995 when any dragging or manipulation of the sediment was done. The emptying of the reservoir until the minimum useful level in /he summer of 1994 and 1995 was more important because of the drying of the sediments from the littoral and the riverine part of the reservoir. 
tantes tanto en la calidad del agua como en la comunidad de organismos. Los resultados obtenidos permiten diferenciar todos estos aspectos que se acaban de indicar y, lo que es más importante, cuantificarlos o al menos ordenarlos por su importancia relativa.

De forma sintética se recordará que el primer factor está asociado a procesos de estratificación y mezcla, así como a la reducción en la concentración de sales totales disueltas que se produce desde invierno a verano, el segundo se relaciona con el balance respiración-producción, que se segregan respectivamente en primavera y otoño, y el tercer factor con la movilización de amonio y materia orgánica del sedimento. Para cada factor se puede calcular el valor de la nueva variable para cada punto de muestreo y representarla en el plano definido por los factores asociados dos a dos. De este modo se tiene una imagen de la evolución del embalse en el tiempo definido por la secuencia anual de muestreo. Esto es precisamente lo que se ha realizado en las figuras 3 y 4 . que sintetizan perfectamente la información más relevante obtenida en este estudio. Se han unido mediante una línea todos los muestreos y se ha obtenido una trayectoria que define la evolución temporal de la estación C 1 a lo largo de 1994 y según los procesos fisicos. químicos y biológicos asociados a cada factor. Se trata en definitiva de una expresión del ciclo anual del embalse que se puede analizar con detalle para ver lo que indican en cada sector del plano. Los primeros muestreos (días 12/94 y 53/94 del año) corresponden al invierno, que como se recordará, se caracterizó por el agua mezclada, temperatura fría y concentración de sales elevada. A partir de este punto la trayectoria temporal nos va llevando hacia la primavera (días 83/94 y 109/94) donde dominan los procesos asociados al segundo factor y que indican un predominio de la respiración sobre la producción y que coinciden con el momento de máxima actividad en el dragado de Barasona. La trayectoria sigue, en solución de continuidad (días 137, 164, 193 y 236 de 1994), hacia el verano, o sea hacia el extremo opuesto del primer factor lo que significa que el agua se ha ido estratificando a la vez que ha aumentado la temperatura y han descendido el oxígeno y las sales totales disueltas. Ahora la trayectoria se dirige hacia la parte positiva del segundo factor, en estos momentos el embalse se está vaciando, se rompe la estratificación y hay un pequeño incremento de la pro- ducción respecto a la respiración. En esta zona de la trayectoria se pierde la continuidad por estar el embalse en la cota mínima de utilización y el agua queda reducida a una solución de sólidos en suspensión difícilmente analizable. En otoño (día juliano 304/94) nuevamente se vuelve a hacer un muestreo y el embalse sigue teniendo una producción más importante que la respiración, mientras que el agua va perdiendo calor y se mezcla. Por último en diciembre (día 335/94) el embalse retorna a unas condiciones similares a las que tenía en enero y se cierra el ciclo correspondiente a 1994. En 1995 la situación fue diferente ya que no hubo dragado y por tanto las diferencias en la trayectoria entre los dos años ilustran este efecto. Como se puede ver en la ya mencionada figura 3 falta la parte del bucle correspondiente al período en el que la respiración tuvo especial relevancia y que coincidió precisamente con el dragado. De esta diferencia se puede concluir que el dragado al liberar materia orgánica y compuestos reducidos estimuló la producción de $\mathrm{CO}$, mientras que este efecto no se produce en los años, como 1995, en los que el embalse se vacía hasta la cota mínima de utilización pero no hay ninguna movilización del sedimento.

La figura 4 muestra la distribución de las muestras en el espacio definido por el primer y tercer factor. Como se puede observar hay una trayectoria de otra forma de ciclo anual que agrupa igualmente la secuencia de muestreo de la estación C1. En este caso la trayectoria define una serie de bucles cuyo significado para el primer eje es el mismo que se ha señalado el párrafo anterior. Es el tercer factor el que tiene interés por estar asociado a la liberación de materia orgánica y amonio del sedimento. El primer bucle sigue una trayectoria ascendente hasta su valor máximo hacia finales de marzo (día 83/94) cuando se alcanza la fase álgida del dragado y va oscilando en función de la intensidad del dragado que duró hasta comienzos del verano. A partir de mediados de julio se inicia un nuevo bucle que se superpone totalmente al anterior y que alcanza su máximo anual a mediados de agosto (día 236/94) cuando se efectuó el último muestreo antes de que el embalse alcanzara su cota mínima de utilización. En estos momentos el agua tenía un color barro por la movilización del sedimento de las orillas y la cola que había quedado en seco y por efecto del viento era resuspendido. El proceso también se 
caracterizó por la liberación de materia orgánica y un incremento del amonio. Con el llenado otoñal del embalse este volvió hacia unas condiciones similares a las de enero. Según este esquema, el tercer factor describe dos situaciones bien definidas y representadas cada una por una trayectoria en bucle de la figura 4. El primero, primaveral es el efecto del dragado, mientras que el segundo es el estiaje producido por el suministro de agua para el regadío. Se puede por tanto diferenciar el comportamiento propio del embalse en función de su uso, del específico y puntual de dragado del sedimento. En 1995 el primer bucle primaveral ha desaparecido lo que expresa que no hay ningún tipo de aportes desde el sedimento, la trayectoria es plana, para ascender nuevamente en al inicio de verano y siguiendo una trayectoria totalmente paralela a la del año anterior.

\section{Heterogeneidad espacial}

Los embalses presentan de forma natural una heterogeneidad espacial según el eje principal del río. Es en este sentido que algunos autores (Margalef, 1983, Thornton et al., 1990) consideran que los embalses son híbridos entre los ríos y los lagos. Según este esquema, la cola mantiene unas características más fluviales, con predominancia del transporte advectivo, mientras que la presa se asemeja más aun lago y tiene una estructuración espacial en sentido vertical con predominio del transporte convectivo (estratificación térmica, intercambios agua-atmósfera, agua-sedimento, migración vertical del zooplancton, etc.) (Straskraba et al., 1993, Uhlmann et al., 1995).

Uno de los objetivos para determinar la importancia del dragado de Barasona ha sido establecer la extensión de la zona afectada por la movilización del sedimento y situar esta información en el esquema de transporte que se acaba de señalar. Una de las consecuencias del dragado es la movilización de una fracción del sedimento que queda resuspendido y circula por los niveles en los que la densidad del agua lo permiten. Cuando el agua esta estratificada el sedimento tiende a mantenerse cerca del fondo y se desplaza horizontalmente por difusión. La entrada del agua del río puede producir un efecto similar al anterior cuando la densidad del agua y la cantidad de sólidos en suspensión hacen que el transporte cola-presa se realiza por los mismos niveles. También durante el estiaje, en el que el embalse alcanza cotas míni- mas, puede haber aporte de sedimento desde la orilla y la cola hacia la masa central de agua que queda en el embalse. Barasona participa de todos los tipos de aportes que se acaban de señalar. Tanto el río Ésera como el Isábena aportan agua que durante buena parte del año (invierno y primavera) es más fría que la superficial y en los periodos lluviosos puede tener importantes cantidades de sólidos en suspensión. Igualmente, desde el inicio de período de regadío hay un vaciado progresivo que reduce la mayoría de los años el volumen hasta la cota mínima de utilización y aumenta considerablemente la turbidez del agua así como la penetración de la luz.

Por lo que respecta al brazo lateral del embalse situado en la margen izquierda hay que destacar la entrada del río Salado de caudal muy pequeño pero con una condiictividad aproximada de $22000 \mathrm{mS} / \mathrm{cm}$. Este valor es muy superior a los que alcanza el agua del embalse en cualquier época del año, pero que en nuestro caso tiene gran interés por servir de trazador de una masa de agua que entra por el fondo (el agua salina es más densa) y puede servir para seguir hasta que punto el brazo lateral es igualmente afectado por la resuspensión del sedimento.

Con objeto de dilucidar el efecto del dragado de las demás posibles causas de aporte de sedimento se han efectuado mediciones verticales metro a metro de una serie de parámetros (temperatura, conductividad, $\mathrm{pH}$, oxígeno, potencial redox y turbidez) en varias estaciones situadas a lo largo del eje principal del embalse $(\mathrm{Cl}$ a $\mathrm{C} 4)$ y del lateral (L1 y L2). De forma específica. la heterogeneidad espacial del embalse y la extensión del mismo afectada por el dragado se ha seguido por el comportamiento conjunto de tres variables (temperatura, conductividad y turbidez) en tres épocas del año en las que la circulación del agua y la actividad del dragado eran muy diferentes.

Con respecto a las variables que se han elegido, la temperatura es la que presenta una mayor estacionalidad. La secuencia de calentamiento del embalse desde invierno a verano no solo describe el ciclo anual consecuencia del clima, sino que refleja el tipo de circulación predominante del agua que entra por el Esera e Isábena en el embalse. En invierno y primavera el agua es algo más fría y circula por el fondo, y parece muy mezclada durante el resto del año debido a que no se estratifica de manera muy marcada durante el 
resto del año. La conductividad se ha elegido por ser una variable muy conservativa que caracteriza bien las diferentes masas de agua por la salinidad. Ya se ha indicado el interés que tiene en el caso del río Salado, pero también es importante para diferenciar el agua del Esera, del Isábena y del embalse. Efectivamente, mientras la entrada de agua es importante la salinidad del embalse y la del conjunto Ésera/Isábena es muy parecida y alrededor de los $400 \mathrm{mS} / \mathrm{cm}$, pero con el estiaje los aportes del Isábena se reducen y la conductividad del agua del embalse desciende hasta el mínimo anual. En estas condiciones es posible diferenciar el agua que entra al embalse de la que se halla en el fondo. Por último, la variable que se ha venido considerando como clave en este estudio, la turbidez, permite observar el efecto conjunto de la resuspensión del sedimento más los aportes del río y de la zona litoral del embalse. La observación complementaria de las tres variables es la que permite observar los patrones de circulación de agua en el embalse y delimitar, de forma aproximada, que área está afectada por el dragado. Esta aproximación es posible porque cada una de las variables sigue leyes físicas diferentes que hace que se comporten de forma independiente, aunque en ocasiones sigan tendencias parecidas. Así, la temperatura del agua sigue la ley de Fourier y las sustancias disueltas se rigen por la ecuación de Fick. Finalmente, la turbidez depende de los sólidos en suspensión y como tales están afectados por la gravedad, de tal forma que para que se encuentren en el agua es necesario que haya turbulencia suficiente para contrarrestar la sedimentación. En este caso la distribución de sólidos en suspensión se queda establecida por la ecuación de Riley et al.,

$$
\frac{d N}{d t}=a N-v^{d N}+A ; \frac{d^{2} N}{d z^{2}}
$$

en la que $a$ es el coeficiente de resuspensión, $\boldsymbol{v}$ la velocidad de sedimentación y $A_{\text {_ }}$ el coeficiente de resuspensión turbulenta. Del estudio comparado de los perfiles obtenidos durantes 1994, se han establecido tres tipos de circulación relacionados con las actuaciones de dragado y vaciado de Barasona.

\section{Fase de circulación}

Corresponde a los períodos del año en que ha llovido y el caudal aportado por los afluentes es importante. Cuando se produce una entrada generalizada de agua por los tres ríos (Ésera, Isábera y Salado), Barasona aumenta considerablemente su volumen y se encuentra muy mezclado tanto en profundidad como horizontalmente. Durante 1994 esta situación se produjo durante los meses de octubre a diciembre como consecuencia de las lluvias otoñales que llenaron el embalse después del estiaje. El muestreo efectuado el 1 de Diciembre refleja este tipo de circulación como puede verse en la figura 5. Según el esquema que se acaba de comentar en otoño de 1994 se diferencia muy bien dos tipos de circulación, el del eje principal del embalse y el del brazo lateral del embalse. En este período los aportes conjuntos del Ésera y el Isábena llegaron muy mezclados como puede verse por en los perfiles de conductividad (valores alrededor de $350 \mathrm{mS} / \mathrm{cm}$ ) y uniformaron el embalse según el eje principal hasta la estación C2. La estación C 1 se diferencia de la anterior por un incremento en profundidad de la conductividad que se explica por los aportes del río Salado. En efecto, si se observan los perfiles de las estaciones L2 y L1 se puede ver que el agua del río Salado, que es más densa por la salinidad, circula por el fondo y, a pesar de que se trata de un caudal muy pequeño, deja sentir su influencia hasta las proximidades de la presa. Desde un punto de vista formal se puede decir que el eje principal del embalse sigue un modelo unidimensional del tipo superficie fondo y con muy poca diferenciación horizontal. Por el contrario el brazo lateral sigue un esquema bicapa con una zona superficial bien mezclada y de características similares a las del resto del embalse, mientras que en el fondo, a partir de los 7-8 m, hay un flujo horizontal desde la entrada del río Salado, que deja sentir su influencia hasta la estación $\mathrm{Cl}$ y posiblemente hasta la presa.

\section{Fase de vaciado}

Una situación que se repite casi anualmente es el vaciado del embalse hasta la cota mínima de utilización durante la fase de regadío. En condiciones normales los aportes de todos los ríos son muy reducidos mientras que el río Salado se seca en agosto. En este período, y en especial cuando el embalse empieza a estar algo vacío, los sedimentos más superficiales quedan al descubierto y aportan al agua del embalse una gran cantidad de sólidos en suspensión. Si no ha llovido desde la 


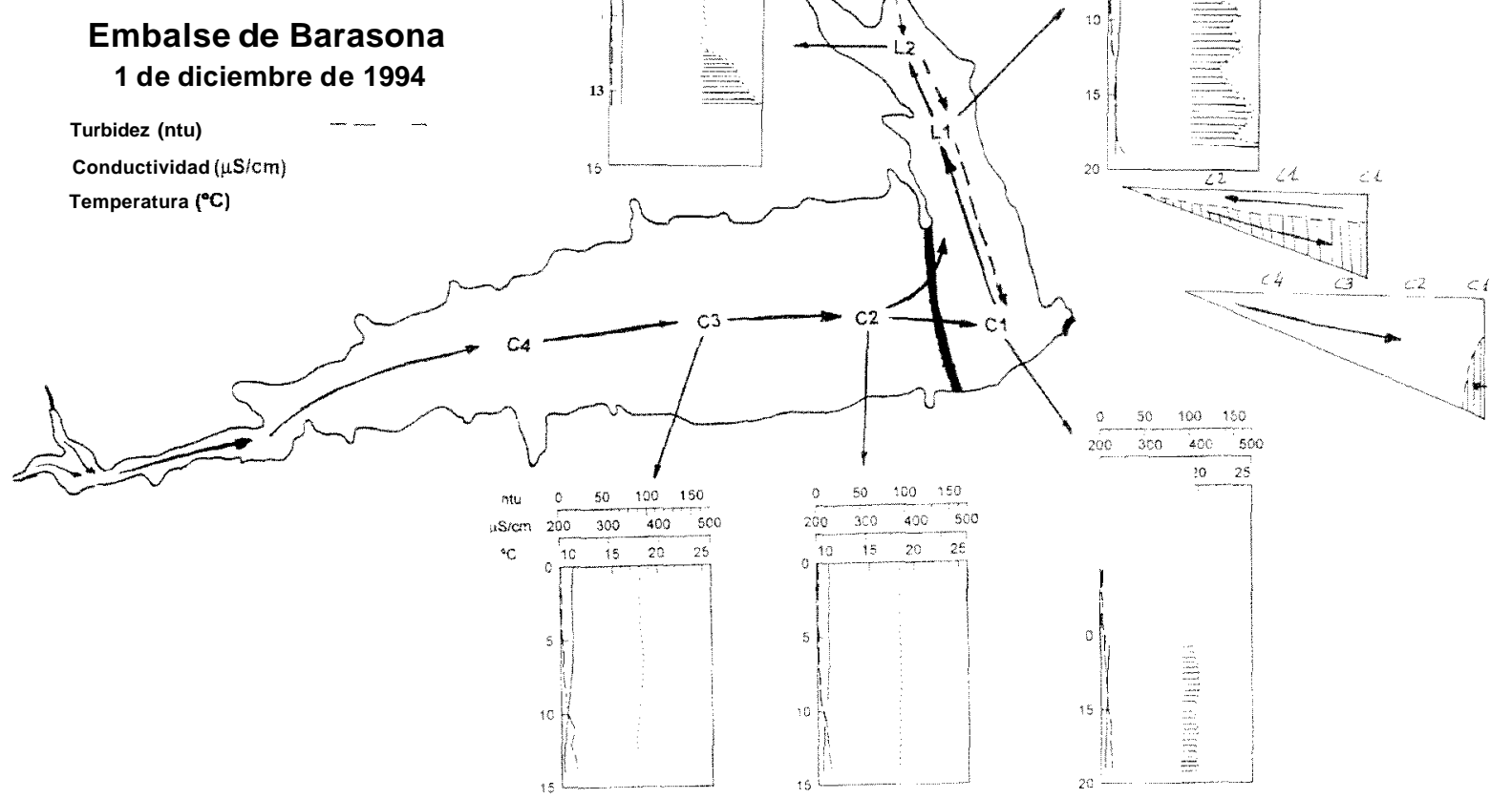

Figura 5. Durante los ineses de invierno el agua de Barasona está mezclada verticalmente y circula a lo largo del eje principal como consecuencia de los aportes de los ríos Ésera e Isábena. En el brazo lateral del embalse se puede apreciar la circulación profunda producida por los aportes del río Salado y que se evidencian por el incremento de conductividad. In winter the vertical profile of Barasona overturns and the runoff coming from the river. Esera and Isabena is full mixed and longitudinal circulation is important. In the late al arm of the reservoir it is possible to ser underflow circulation because of the inputs of the river Salado, that can be appreciated by the incrase of conductivity close to the bottom.

primavera los aportes del Isábena son muy pequeños y por tanto la contribución de esta agua muy mineralizada a la conductividad del embalse es poco importante. Durante 1994 a los efectos directos del estiaje hay que añadir el dragado del embalse y por tanto una resuspensión adicional de sedimento. El esquema típico de este período del año se puede ver en la figura 6 correspondiente a mediados de Julio. En Agosto Barasona tenía una turbidez aún mayor, todo el embalse tenía un color grisáceo $(0.3 \mathrm{~m}$ de profundidad de visión del disco de Secchi) y el agua no llegaba a las estaciones C4 y L2. El aspecto más característico de esta fase es que el agua que entra al embalse, principalmente del Ésera, circula por el fondo ya que los sólidos en suspensión hacen aumentar su densidad. En la figura 6 se observa que los perfiles de conductividad descienden a valores próximos a $200 \mathrm{mS} / \mathrm{cm}$ a partir de los 5 6 metros, coincidiendo con una suave termoclina. La turbidez general del embalse ha aumentado desde primavera de forma paralela a como se ha ido vaciando y en estos momentos el agua superficial tiene valores muy uniformes de 15-17 ntu. Por el contrario, al llegar a los metros más próximos del sedimento se observa un brusco incremento de la turbidez que se debe al dragado del embalse. El brazo lateral presenta un comportamiento totalmente diferente. En Julio el río Salado esta seco pero se puede detectar su efecto 


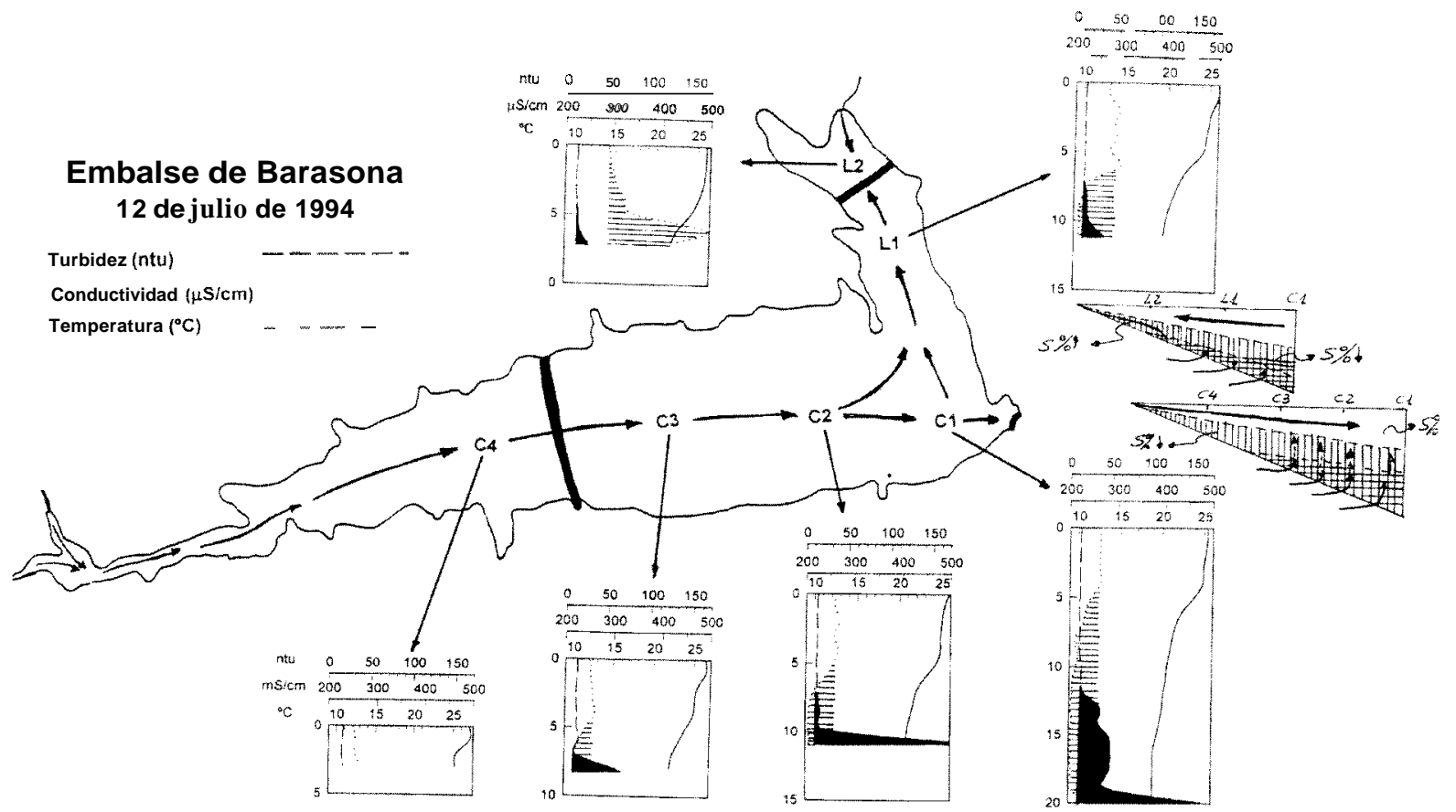

Figura 6. El vaciado de Barasona hasta su cota mínima de utilización se produce casi todos los años en período de regadío. Durante Julio de 1994se apreciaron dos vías de aporte de sólidos en suspensión. Por un lado hay un aumento generalizado de la turbidez del embalse por movilización de los sedimentos litorales y de la cola y por otro hay un resuspensión del sedimento por efecto del dragado. Este último aporte se aprecia por la cúpula de turbidez sobre el fondo y que es más importante en la estación C1 aunque también se aprecia en las estaciones C2, C3 y L1. Because of the water supplyfor irrigation, in summer Barasona is emptied until its useful level almost all the years. In July of 1994 the particulate matter came for two ways. One was produced by the contribution of sediments coming from the littoral und riverine zone and the other was because of the dragging effect. The second type of contribution can be appreciated brcuuse of the dome of turbidity close to the bottom in station $C$, although it can be also seen in stations $\mathrm{C} 2, \mathrm{C} 3$ and LI.

en la parte del embalse más próxima, estación L2, por el incremento de la conductividad con respecto al resto de las estaciones muestreadas. La estación L 1 muestra unos perfiles de temperatura, conductividad y turbidez similares a los de las estaciones $\mathrm{C} 1, \mathrm{C} 2$ y $\mathrm{C} 2$ mostrando una influencia de la masa de agua principal del embalse.

En resumen, a partir del incremento de la turbidez se puede observar que el efecto del dragado se deja sentir hasta la estación C3 y L1 en forma de una capa de agua pegada al sedimento. Parcialmente mezclada con esta capa, pero hasta la parte inferior de la termoclina se sitúa una masa de agua de baja conductividad resultado del descenso en el caudal de Isábena. Por último el agua superficial no solo tiene una temperatura más elevada, sino que la conductividad corresponde a la que había hasta principios de verano y a que es una mezcla de los aportes del Ésera y el Isábena. Toda la masa de agua es ligeramente turbia.

\section{Fase de dragado}

El dragado es la actuación directa más importante que se ha efectuado en Barasona durante 1994 y el objetivo principal de este estudio. Aunque el dragado se inició a finales de invierno, en sus primeras etapas su efecto fue muy poco importante hasta abril en que se cambió de técnica. Desde abril hasta junio se realizó la extracción más importante de sedimento y por tanto es la fase que se puede considerar como de mayores consecuencias para el embalse. Estudios previos realizados en embalses franceses (Cardinal, 1989) y americanos (Cooke et al., 1993) indican que además de la resuspensión del sedimento hay una liberación y disolución de muchas de las sustancias acumuladas en él (amonio, metales pesa- 


\section{Embalse de Barasona 19 de abril de 1994}

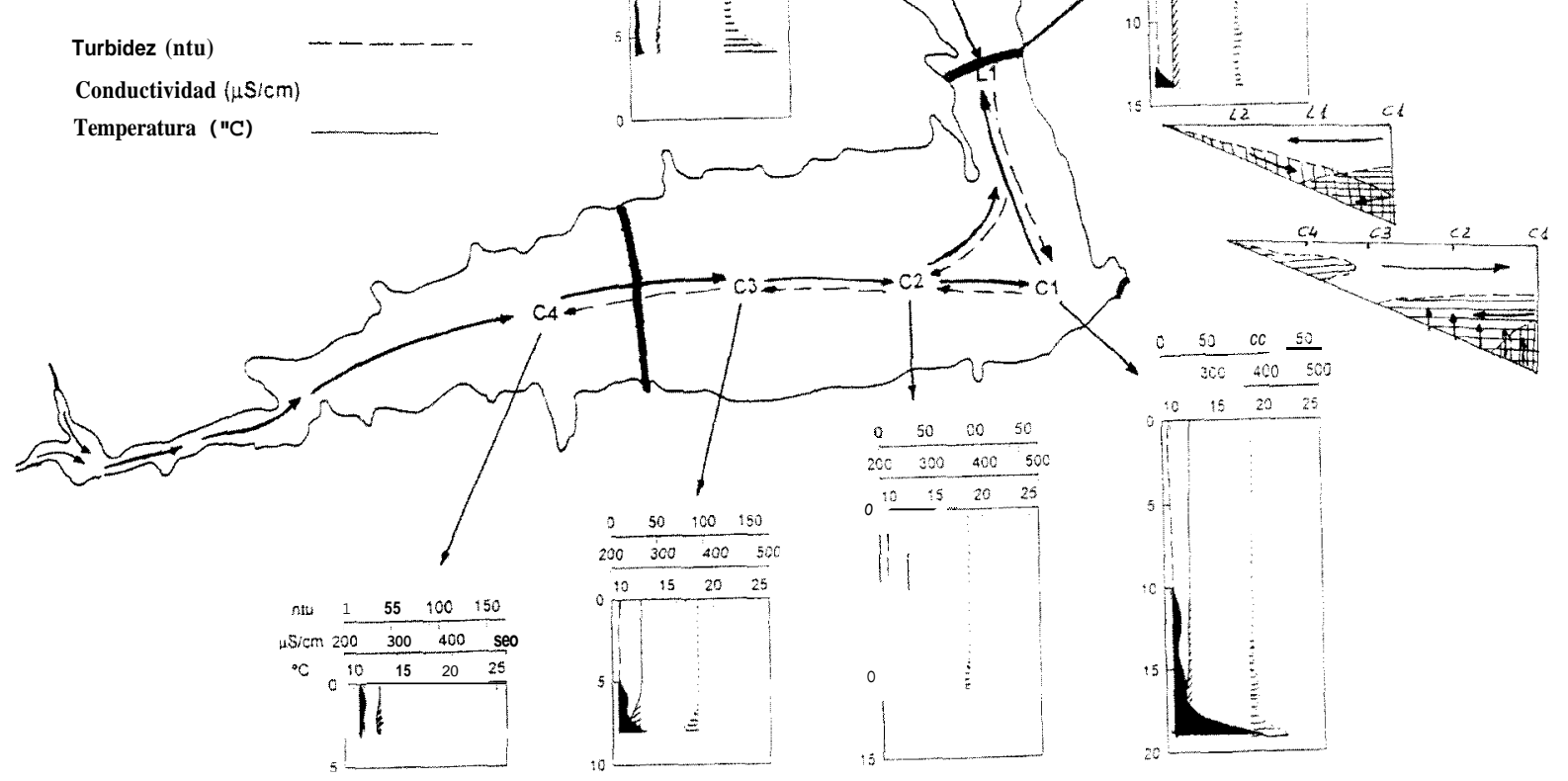

Figura 7. Heterogeneidad espacial del Barasona en el inicio de la fase intensa del dragado. Se aprecia una cúpula de agua turbia que va desde la presa a la cola y brazo lateral del embalse. En la estación $\mathrm{Cl}$ el agua turbia llega hasta 10 metros de la superficie y se va hundiendo hacia la cola del embalse. En el brazo lateral se observa un efecto similar pero mucho menos marcado. En ningún momento del dragado el sedimento resuspendido alcanzó la superfície o a la capa fótica. Spatial heterogeneity of Barusona during the period of intensive dragging. It is possihle to see the dome of turbid water along ihe entire main axis oftlie reservoir atid of its lateral arm. In station $C l$ the dome arrives until $10 \mathrm{~m}$ of the surface and sinks towards the riverine part of the reservoir. In the lateral urm the same but less intensive effect is produced. In any time of the dragging period, the resuspended sediment arrived to surface or to the photic zone.

dos, fosfatos, materia orgánica). Los análisis efectuados en el agua próxima al sedimento muestran que en Barasona este efecto es prácticamente despreciable. Este escaso efecto se debe en parte a que se trata de un sedimento de tipo limo, muy mineral, con muy poca materia orgánica y totalmente oxidado incluso a niveles profundos. El vaciado estival del embalse hasta la cota mínima de utilización que se produce muchos años determina que gran parte de la superficie del sedimento quede en contacto con la atmósfera. Además, Barasona es oligo-mesotrófico lo que determina unos aportes pequeños de materia orgánica y de metales hacia el sedimento.
Para ilustrar el efecto del dragado se ha escogido como situación más representativa a la que presentaba el embalse en Abril ya que corresponde al período de mayor actividad extractora de sedimento a la vez que los aportes de los ríos eran poco importantes. Como puede verse en la figura 7, destaca la resuspensión de sedimento, que se evidencía por la presencia de una capa de agua profunda y densa que alcanza desde el fondo hasta los 10 metros de la superficie en la estación $\mathrm{C} 1$ y hasta los 5 metros en la C2 y C3. La imagen que ofrecen estos perfiles es la de una cúpula de agua turbia que llega más cerca de la superficie en el punto de dragado, próximo a la presa, y que 
va descendiendo a medida que los perfiles se alejan de él, si bien su efecto se manifiesta hasta la estación C3. En paralelo, pero en dirección contraria, hay una entrada de agua desde los ríos Ésera e Isábena que se desliza por encima de la capa de agua turbia hasta alcanzar la presa. El brazo lateral de Barasona también muestra un patrón de circulación similar. Por un lado está el efecto de los aportes del río Salado detectable por la conductividad más elevada del agua del fondo y que se puede detectar hasta la estación C1. En dirección contraria se aprecia el movimiento del agua turbia desde la estación $\mathrm{Cl}$ a la L1, aunque con un efecto mucho menor que el que se produce en el eje principal del embalse. Es como si la cúpula, que se ha mencionado antes, descendiese más bruscamente en el sentido del brazo lateral y no pasase de la estación L1.

\section{CONCLUSIONES}

A lo largo de los años 1994-95 el embalse de Barasona ha sido sometido a diferentes tipos de actuaciones entre las que cabe destacar el dragado de la zona próxima a la presa durante el primer año y su vaciado total por apertura de los desagües de fondo en octubre de 1995. A estas actuaciones de carácter "excepcional" hay que añadir el vaciado hasta su cota mínima de utilización durante los meses de verano, que se produce la mayoría de los años que no son demasiado lluviosos durante esta estación. En este estudio se ha pretendido diferenciar estos tres efectos tomando como referencia los procesos más importantes que se producen en el ciclo anual del embalse.

Según los resultados obtenidos las tres actuaciones que se han detectado se han caracterizado por los siguientes efectos:

- El dragado ha constituido una actuación sobre los sedimentos no alterados desde hace bastantes años y que no han estado en contacto con la atmósfera. El efecto más inmediato del dragado ha sido la una pequeña resuspensión del sedimento con liberación de materia orgánica, nitrógeno amoniacal y metales, que ha alcanzado hasta la tercera parte de la longitud del eje principal del embalse y a la mitad del brazo lateral. La turbidez no ha alcanzado en ningún momento a la capa fótica y el cambio más importante producido ha sido un incremento de la respiración.

- El vaciado del embalse hasta la cota mínima de utilización es un proceso periódico que se produce durante el estiaje. El efecto más importante es un incremento de los sólidos en suspensión, que limitan la penetración de la luz en el agua a unos pocos centímetros de la superficie. Como que se trata de sedimentos que de forma repetida están en contacto con la atmósfera, contienen poca materia orgánica y nutrientes debido a los lavados sucesivos del agua intersticial. En cada vaciado de este tipo hay un pequeño incremento en la concentración de amonio y metales disueltos, aunque no de la respiración. Este efecto es más importante por la extensión de los sedimentos afectados que por las características propias del mismo. La resuspensión de los materiales más finos hace que la turbidez del agua sea muy elevada hasta la superficie y que la luz sea limitante, motivo por el que la producción primaria no aumenta significativamente.

- El vaciado total del embalse ha sido una actuación única que ha afectado a los sedimentos de la zona más profunda del embalse y que por este motivo no habían estado previamente en contacto con la atmósfera. Su contenido en materia orgánica, nutrientes, especialmente amonio, y metales es muy elevado. Con el vaciado todos estos compuestos que se encontraban en el agua intersticial se movilizan con los lixiviados, y se van oxidando en su recorrido hacia el río Esera, con lo que su efecto inmediato sobre el embalse es nulo. A medida que el sedimento se va secando va adquiriendo unas características similares a las del que se encuentra en la cola. Por este motivo es de prever que sucesivas aperturas del desagüe de fondo tendrán un efecto mucho menor, tantq sobre el embalse como en el tramo inferior del Esera. Al llenarse nuevamente el embalse no se apreciaron diferencias significativas a las que había tenido Barasona antes de su vaciado.

\section{AGRADECIMIENTOS}

El Presente trabajo ha sido realizado con la financiación de la Confederación Hidrogáfica del Ebro, del Centro de Estudios y Experimentación de Obras Públicas (CEDEX) y de un convenio de FCC con la Universitat de Barcelona. El autor de- 
sea agradecer la colaboración de Jordi Sacristan, Roger Bartra y Juan Carlos García Pradell en los trabajos de recogida y preparación de las muestras asi como en las mediciones "in situ". Los Servicios Científico-Técnicos de la Universitat de Barcelona han realizado una parte destacada de los análisis químicos de las muestras de agua.

\section{BIBLIOGRAFÍA}

APHA. 1989. Standard Methods for the Examination of Water and Wastewater, 17th ed. Amer. Public Health Assoc., Inc. N.Y.

ARMENGOL, J., M. CRESPO, J.A. MORGUÍ \& A. Vidal. 1986. Phosphorus budgets and forms of phosphorus in the Sau reservoir sediment: An interpretation of the limnological record. Hydrobiologia 143: 331-336.

ARMENGOL, J., J.L. RIERA \& J.A. MORGUÍ. 1991. Major ionic composition in the Spanish reservoirs. Verh. Internat. Verein. Limnol. 24: 1363-1366.

CARDINAL, H. 1989. Bilan des Recherches et Recomendations en Matière de Vidanges de Retenues: Procedure LIVRE. Direction des Études et Recherches. EDF. HE-3 1/88-20.

COOKE, D.G., E.B. WELCH, S.A. PETERSON \& P.R. NEWROTH. 1993. Restoration and Management of Lakrs and Reservoirs., $2^{\text {ond }}$ ed. Lewis $\mathrm{Pu}-$ blishers. Boca Raton.

GOLTERMAN, H. L., R.S. CLYMO \& M.A.M. OHNSTAD. 1978. Methods for Physical and Chemical Analysis of Fresh Waters. IBP Handbook $n^{\circ} 8$. Blackwell Scientific Publications. Oxford.

MACKERETH, F. J. H., J. HERON \& J.F. TALLING. 1978. Water analysis: Some revised methods for limnologists. FBA. Scientific Publications $n^{\circ} 36$. The Ferry House.

MARGALEF, R. 1975. Typology of reservoirs. Verh. Internat Verein. Limnol. 19: 1841-1848.

MARGALEF. R. 1983. Limnología. Barcelona. Ed. Omega. Barcelona.
MARGALEF, R., D. PLANAS. J. ARMENGOL, A. VIDAL, N. PRAT, A. GUTSET,J. TOJA y M. ESTRADA. 1976.Limnología de los embalses españoles. Dirección Gral. Obras Hidráulicas. MOPU. Madrid. 422 pp.

MORGUÍ, J. A., J. ARMENGOL, y J.L. RIERA. 1990. Evaluación limnológica del estado de los embalses españoles: Composición iónica y nutrientes. Terceras Jornadas Españolas de Presas, Barcelona: 652-668 pp.

NURNBERG, G. 1984. The prediction of internal pliosphoi-us in lakes with anoxic hypolimnia. Limnol. Ocenogr. 29: 111-124.

NURNBERG, G. \& R.H. PETERS. 1984. Biological avalability of solute reactive phosphorus in anoxic and oxic freshwaters. Can.J.Fish.Aquat.Sci. 41:757-765.

PRESS, W. H., B.P. FLANNERY, S.A. TEUKOLSKY \& W.T. VETTERLING. 1989. Numerical Recipes. The Art of Scientific Computing. Cambridge University Press. Cambridge.

RIERA, J.L., D. JAUME, J. DE MANUEL, J.A. MORGUÍ \& J. ARMENGOL. 1992. Patterns of variation in the limnology of Spanish reservoirs: A regional Study. Limnetica 8: 111-123.

RILEY, G. A., H. STOMMEL \& D.F. BUMPUS. 1949. Quantitative ecology of the plankton of the Western Atlantic. Bull. Bingharn Ocean.Coll. 12:1-169.

STRASKRABA, M., J.G. TUNDISI \& A. DUNCAN. 1993. State-of-the-art of reservoir limnology and water quality management. In:Comparative Reservoir Limnology und Water Quality Management. M. Straskraba, J. G. Tundisi \& A. Duncan (eds.): 213-288. Kluwer Academic Publishers. Dordrecht.

THORNTON, K. W., B.L. KIMMEL \& F.E. PAYNE. 1990. Reservoir Limnology: Ecological perspectives. John Willey \& Sons, Inc. N.Y.

UHLMANN, D., M. HUPFER \& L. PAUL. 1995. Longitudinal gradients in the chemical and microbial composition of the bottom sediment in a channel reservoir (Saidenbach R., Saxony). Int.Revue ges.Hydrobiol. 80: 15-25.

WETZEL, R. G. \& G.E. LIKENS. 1991. Limnological Analyses, $2^{\text {ond }}$ ed. Springer-Verlag. N.Y. 
